\section{Pneumatic perforation of the cecum during diagnostic sigmoidoscopy}

An 80-year-old male patient underwent sigmoidoscopy to perform polypectomy. A complete colonoscopy 4 months before, had shown a $2 \mathrm{~cm}$ sessile, ulcerated polyp in the sigmoid colon, which was not resected. By this time, a stenotic mass lesion was found at the same location. Biopsies were taken and exploration finished, and the patient was referred for surgery with the diagnosis of colorectal carcinoma. Six hours after sigmoidoscopy, the patient returned to the hospital with acute abdominal pain and tenderness. X-ray showed pneumoperitoneum, undergoing emergency laparotomy. A $15 \mathrm{~cm}$ rupture along the cecum wall was observed. No signs of perforation were seen in the sigmoid area. Subtotal colectomy was carried out. Six months later, the patient is alive and being followed up by both surgeons and oncologists. The final diagnosis was "moderately differenced adenocarcinoma infiltrating mesenteric adipose tissue, with peritumoral and mesenteric lymph nodes extension".
Colon perforation is an uncommon complication during diagnostic colonoscopy. The rate is as low as $0.02 \%$ of all cases [1]. Perforation is more likely to occur during therapeutic procedures [2], or if an underlying colonic disease is present. Another unusual mechanism is barotrauma caused by excessive insufflation and retention of air [3]. Our case might be included in the latter group: no therapeutic intervention was made, and no concomitant disease was present. The only underlying factor might have been the patient's age, but colonoscopy appears to be safe in the elderly [4]. The presence of a straightened colon lumen could have promoted air accumulation and blocked its elimination, inducing excessive pressure at the right colon, causing cecal perforation. The management of these perforations is, in most cases, surgical. However, a conservative approach can be taken in selected cases. In our patient, surgical therapy was decided because of the peritoneal irritation and with the intention of curing the sigmoid neoplasia.

Endoscopy_UCTN_Code_CPL_1AJ_2AB
D. Sánchez-Muñoz ${ }^{1}$, C. Ortiz-Moyano', M. Ramírez-Martín del Campo ${ }^{1}$, D. Núñez-Hospital ${ }^{1}$, D. García-Romero ${ }^{1}$, C. Delgado², P. Guerrero-Jiménez ${ }^{1}$, J. L. Larraona-Moreno ${ }^{1}$, M. Romero-Gómez ${ }^{1}$

1 Unit for the Clinical Management of Digestive Diseases, Hospital Universitario de Valme, Sevilla, Spain

2 Surgery Department, Hospital Universitario de Valme, Sevilla, Spain

\section{References}

1 Ettersperger L, Zeitoun P, Thiefin G. Colonic perforations complicating colonoscopy. Apropos of 15 consecutive cases observed over 16 years. Gastroenterol Clin Biol 1995; 19: 1018 - 1022

2 Vernava AM $3^{\text {rd }}$, Longo WE. Complications of endoscopic polypectomy. Surg Oncol Clin N Am 1996; 5: 663-673

3 Woltjen JA. A retrospective analysis of cecal barotrauma caused by colonoscope air flow and pressure. Gastrointest Endosc 2005; 61: $37-45$

4 Arora A, Singh P. Colonoscopy in patients 80 years of age and older is safe, with high success rate and diagnostic yield. Gastrointest Endosc 2004; 60: 408-413

Bibliography

DOI $10.1055 / \mathrm{s}-2007-966484$

Endoscopy 2007; 39: E183

(c) Georg Thieme Verlag KG Stuttgart · New York . ISSN 0013-726X

Corresponding author

\section{Sánchez-Muñoz, MD}

Unit for the Clinical Management

of Digestive Diseases

Hospital Universitario de Valme

Carretera a Cádiz S/N

41014 - Sevilla

Spain

Fax: +34-955015889

dsanchezm@wanadoo.es 